\title{
Flooding increases respiration and sugar content in the tomato stem: survival strategy or "aimless" response?
}

\author{
Francesco Mignolli ${ }^{1}$, Javier Barone ${ }^{1}$, and Maria Laura Vidoz ${ }^{1}$ \\ ${ }^{1}$ Instituto de Botánica del Nordeste
}

February 13, 2021

\begin{abstract}
With flooding being one of the numerous challenges that ecosystems face throughout the world, plants are therefore obliged to adopt plastic responses in order to cope with this environmental constraint. When flooded, the tomato hypocotyl undergoes profound changes that entail rearrangements in its physiology and metabolism. In this work, we observed that, although soil flooding markedly dampens root respiration, the submerged hypocotyl surprisingly enhances oxygen consumption in spite of hypoxic conditions. Several pieces of evidence indicate that the respiratory pathway is indeed promoted in submerged stems. Besides, underwater hypocotyls are shown to accumulate sugars. Girdling and feeding experiments revealed that leaf-derived sucrose is metabolized and channelled to maintain respiration in underwater hypocotyls. Our data suggest that high respiration is required for sucrose unloading from phloem, since inhibition of hypocotyls respiration significantly prevents sugar buildup. As substrate availability increases, respiration is fuelled even more, leading to a sustained allocation of sugars to flooded hypocotyls.
\end{abstract}

\section{Hosted file}

Main document.pdf available at https://authorea.com/users/395436/articles/508709-floodingincreases-respiration-and-sugar-content-in-the-tomato-stem-survival-strategy-or-aimlessresponse 

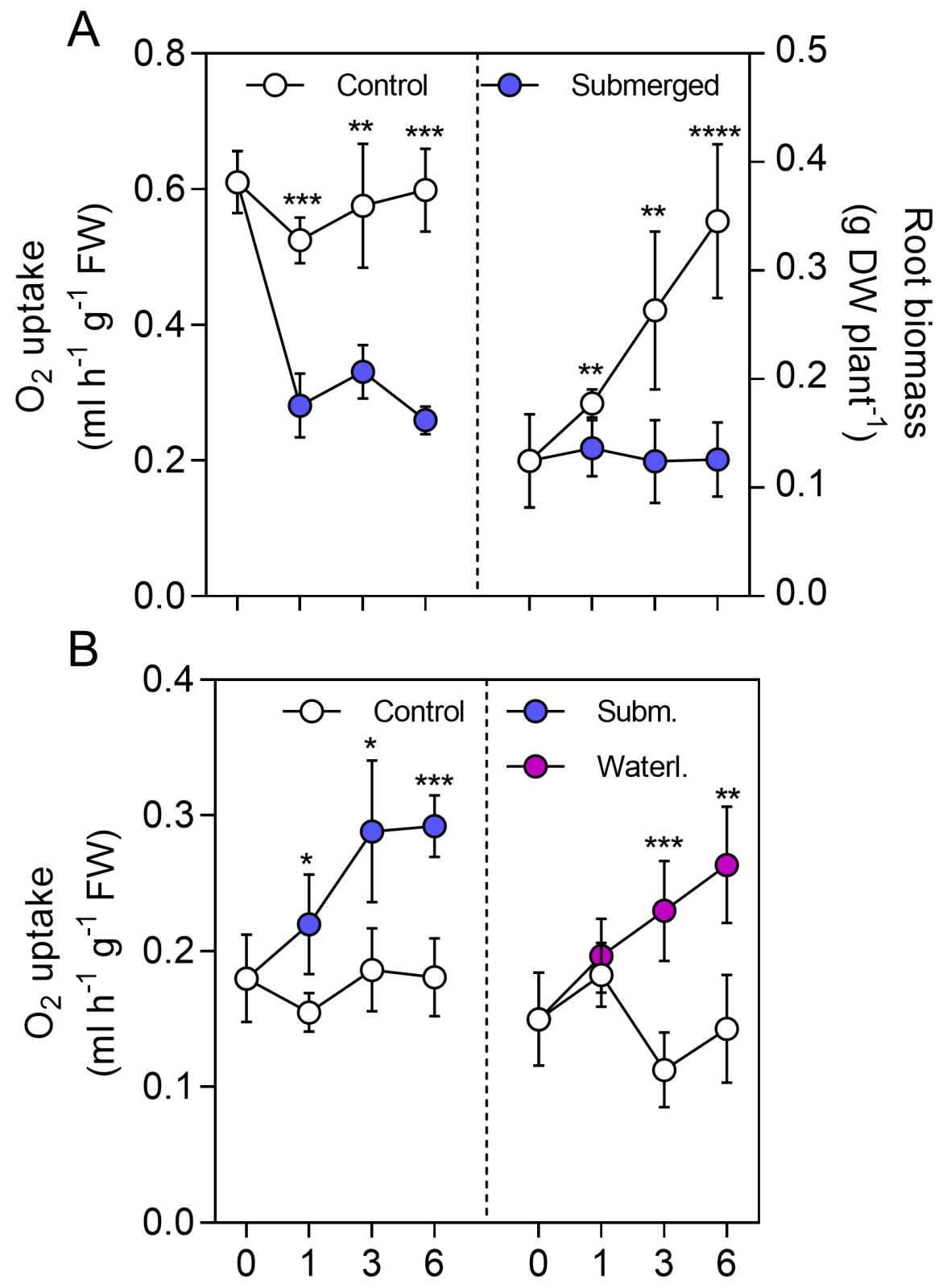

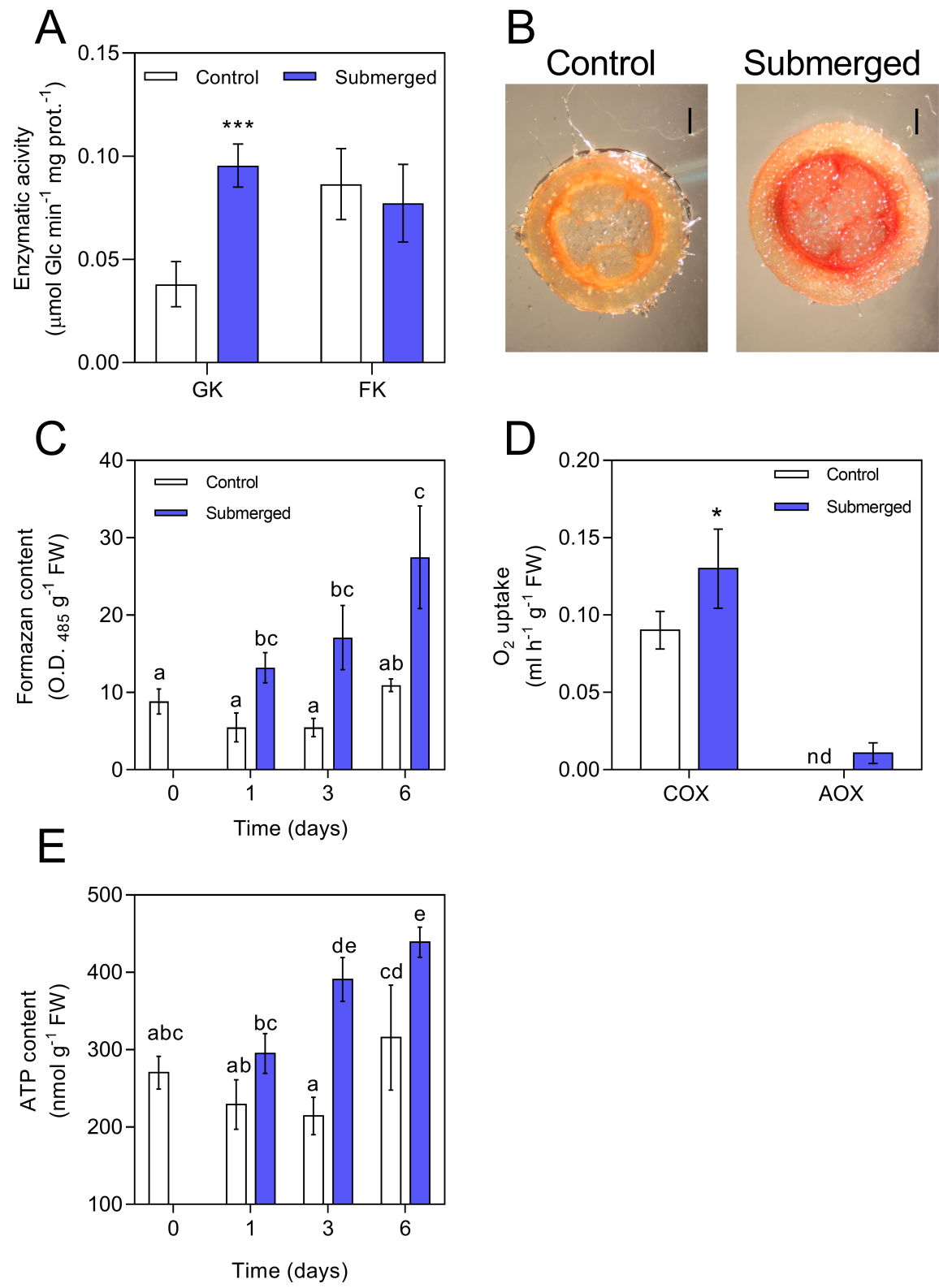
A

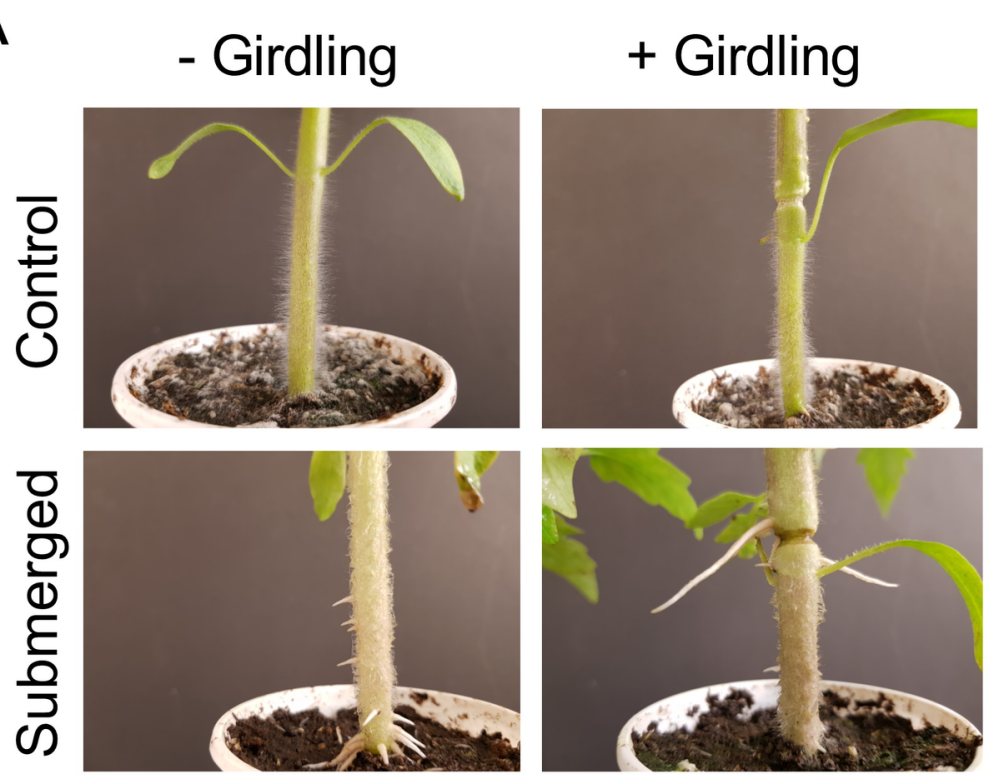

B

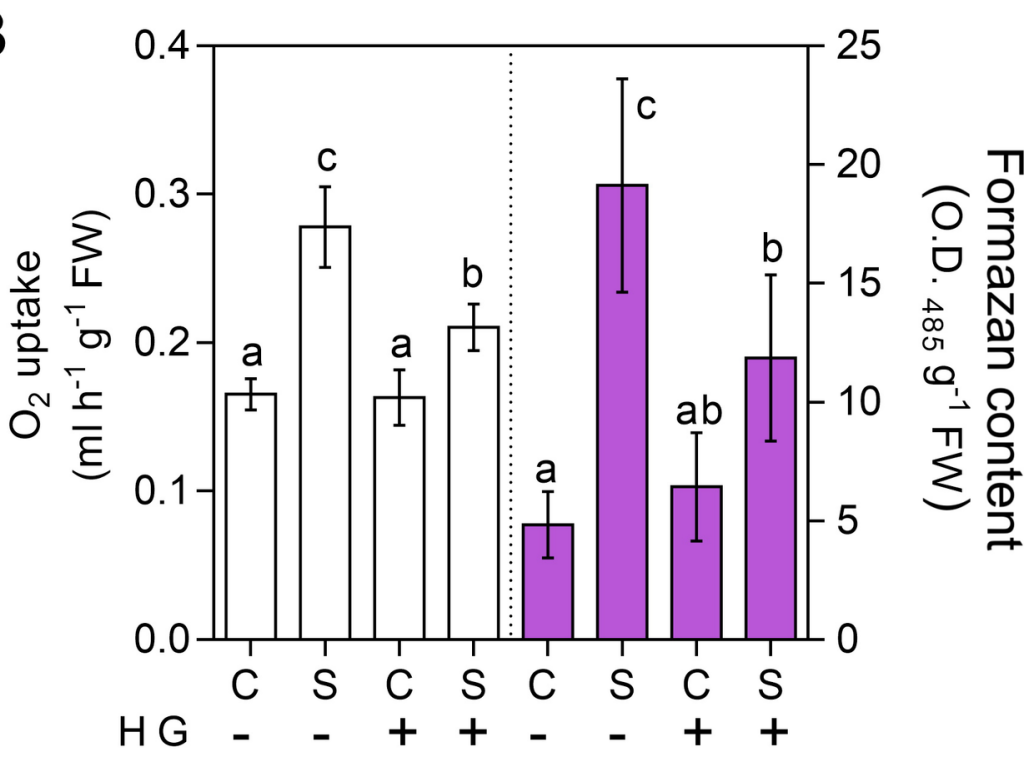


A
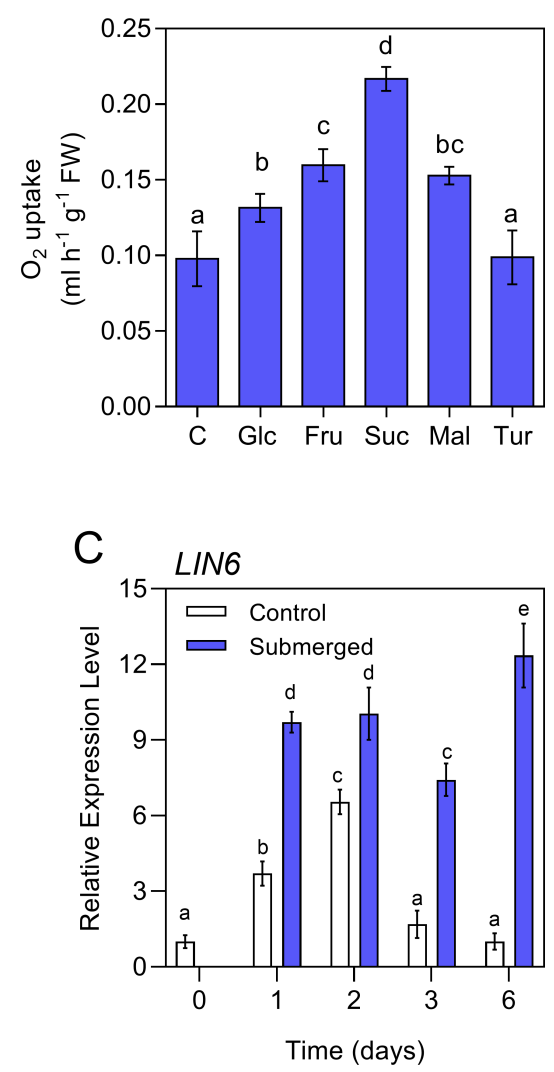

B
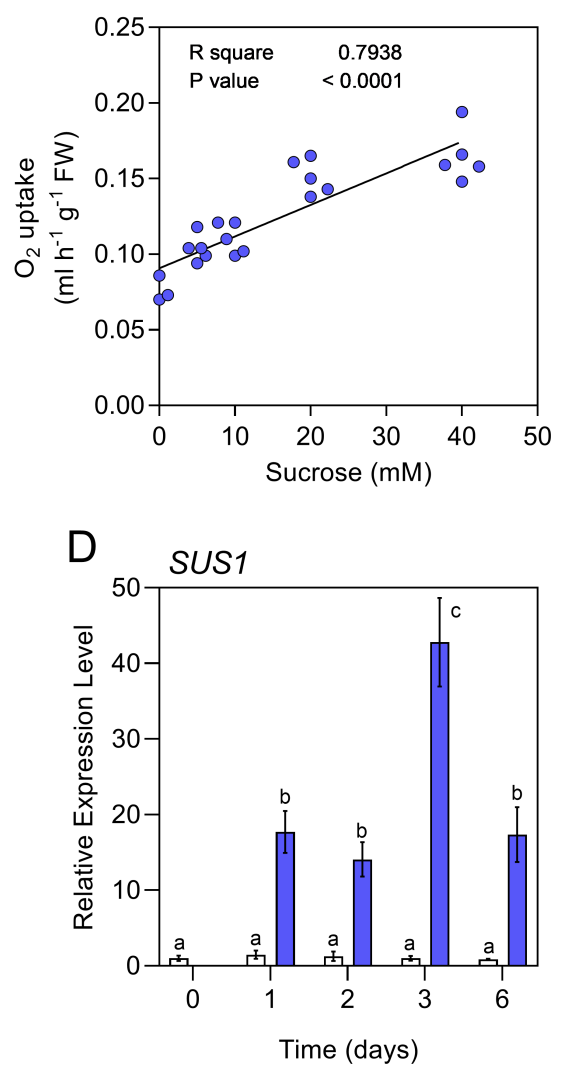
A

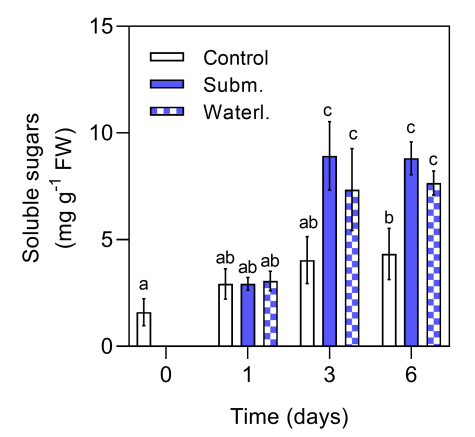

C

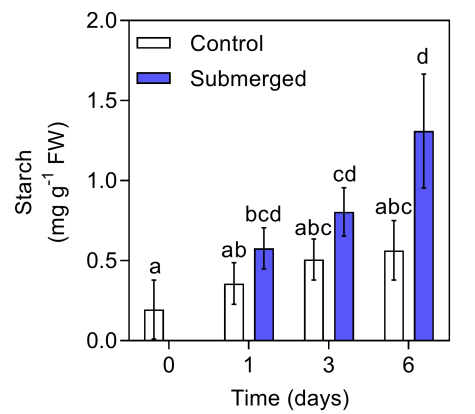

E

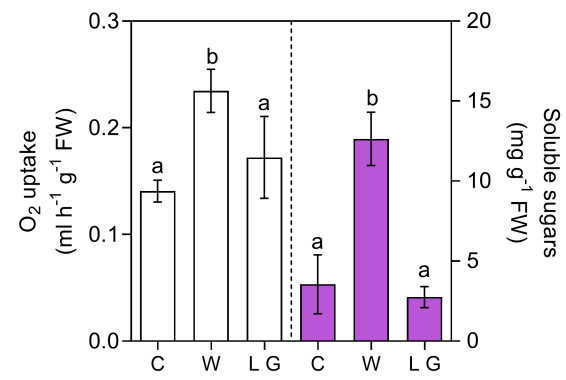

B

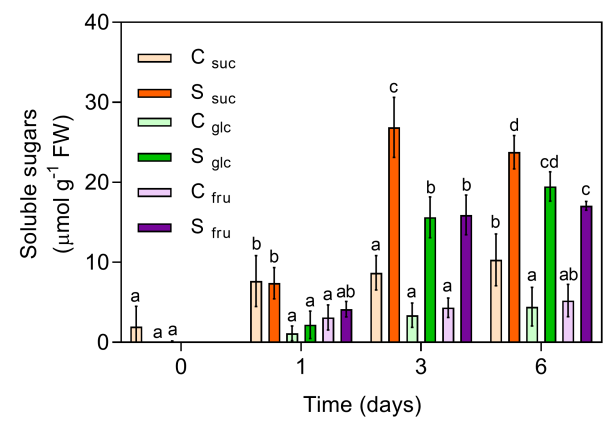

D

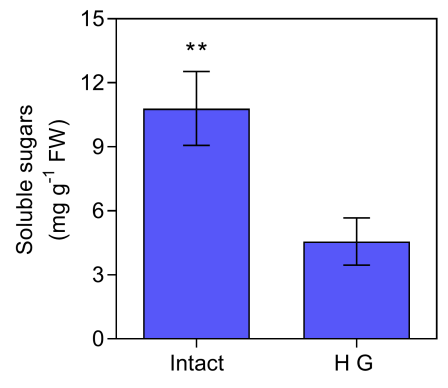

F

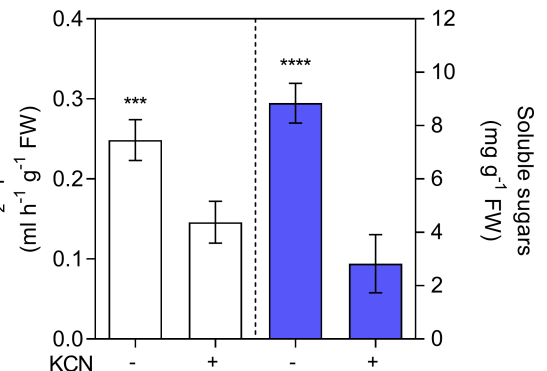




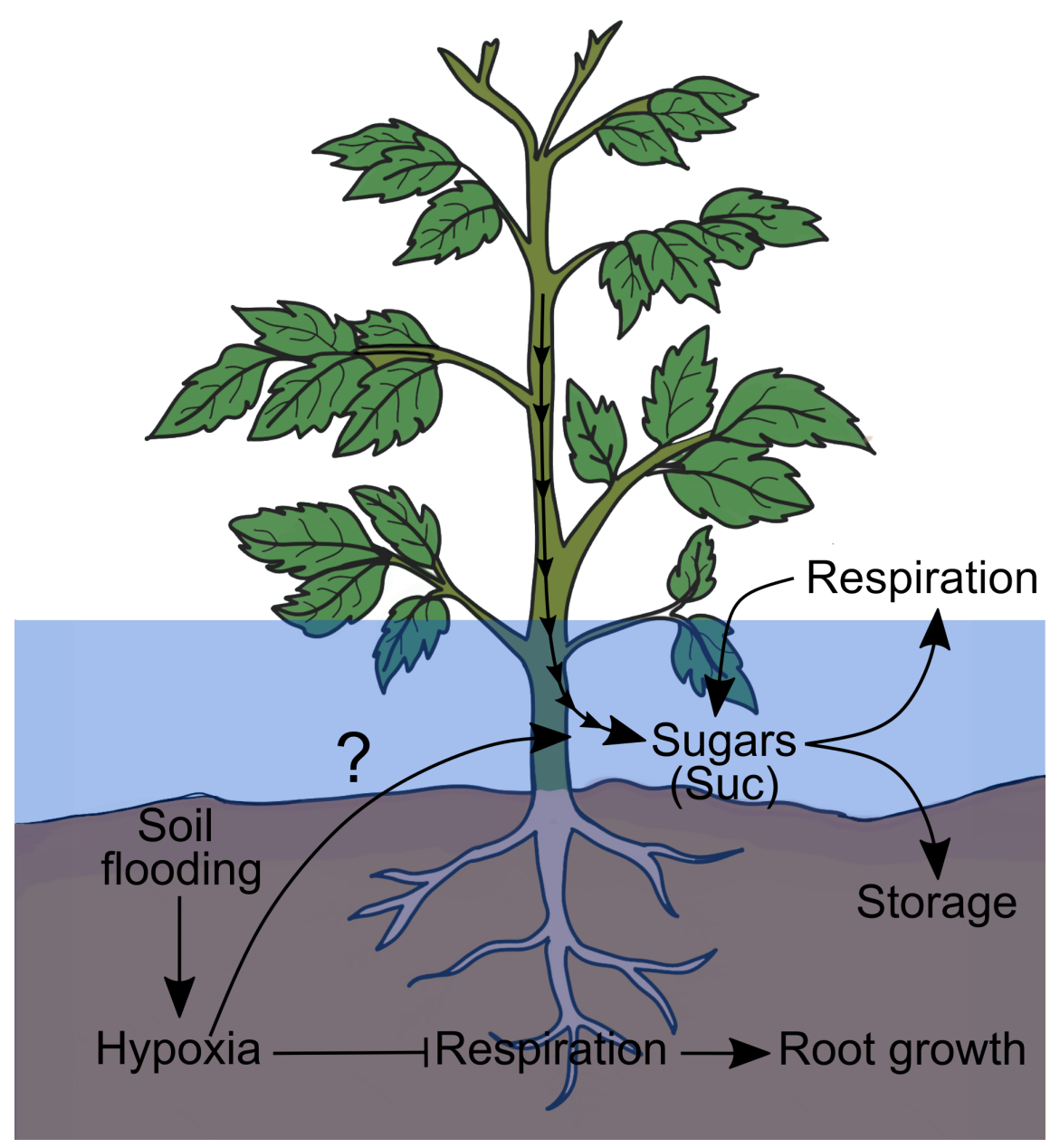

